\title{
Analysis on the Feasibility of the Development of Cultural Tourism Resources in Pingtan Tourist Island
}

\author{
Milong Wu \\ Teaching Development Center \\ Fuzhou University of International Studies and Trade \\ Changle, China \\ 512161502@qq.com
}

Xiao Zhao

Department of Public Education

Fuzhou University of International Studies and Trade Changle, China

1530924352@qq.com

\author{
Chunmei Li \\ Teaching Development Center \\ Fuzhou University of International Studies and Trade \\ Changle, China \\ 1825487339@qq.com \\ Xiaofang Guo* \\ School of Finance and Accounting \\ Fuzhou University of International Studies and Trade \\ Changle, China \\ 285889359@qq.com
}

\begin{abstract}
As a new mode of tertiary industry that China supports and develops vigorously, the integration and development of culture and tourism industry are of great significance to promote the development and upgrading of the entire national economy and structural transformation. Based on the development of tourism economy in Pingtan International Tourism Island in recent years, this paper analyzes the feasibility of developing cultural tourism resources and developing the cultural tourism industry in Pingtan Tourism Island.
\end{abstract}

Keywords - cultural tourism; tourism resources; Pingtan economy; cultural industry

\section{INTRODUCTION}

Since the 18th National Congress of the Communist Party of China, the Party Central Committee has proposed "to promote the integration and development of cultural industries with tourism, sports, information, logistics, and construction industries. "On March 5, 2019, Premier Li Keqiang pointed out in the government report:

"At the critical moment of building a culture-powerful country, the vast number of cultural and tourism workers must not only handle cultural tourism and tourism culture, cultural resources and tourism resources, but also coordinate the relation of public cultural services and tourism. At the same time, attention should be paid to the coordination of the important relationship between the cultural industry and the tourism industry, cultural creative products and tourist souvenirs, foreign cultural exchanges and foreign tourism promotion Last but not least, you should strengthen top-level design, innovative ideas, and form new kinetic energy for integration and development to make new contributions to the strategy of cultural power. In the 2019 Pingtan County Government Work Report, vigorously developing the cultural, recreational and sports industry was listed as a key task. First of

2018 provincial college student innovation training program in Fujian province all, focus on "big tourism" and highlight new cultural innovation, new tourism and new consumption. Pay attention to build island tourism and leisure and focus on the "big culture". Besides, we will make a top-level design for the development of new media industries for film and television, and start to develop a cross-strait film and television industry base. What's more, accelerating the construction of the South Island Language Archaeological Research Base and promoting the preliminary work of the Hai tan Strait Underwater Relics Park. Finally, we will create "The Ten village of Taiwan", which is open to the public, promotes the landing of projects such as the International Film and Television Exchange Center. [1]Therefore, with the support of the policy background, I have studied the development of tourism economy in Pingtan Tourism Island in recent years, whether the development of cultural tourism resources will have a driving effect on the economic development of Pingtan Tourism Island, and the development of Pingtan and want to contribute to the economic development of Pingtan.

\section{LITERATURE REVIEW}

Cultural tourism is the experience of the public's cultural connotation of tourism resources. The perception that cultural tourism brings to the public is a new, educational and aesthetically pleasing activity. In the process of building an international tourist island, according to the characteristics of local cultural resources, explore different research routes, research and develop cultural research tourism products, and construct a Pingtan cultural research tourism system, which achieves not only cultural resource integration, cultural and tourism industry combination but also tourist spiritual experience. Tourism culture involves many fields, such as the cultural industry, which is one of the important signs to promote the development of the national economy.[2] (Yuxia $\mathrm{Li}, 2018$ ) The cultural industry can make the development of 
tourism resources realize its marketization and promote the development of tourism. The tourism industry can enrich its content through the cultural industry, which enhance its cultural content and improve the quality of the tourism industry.[3] (Yonggui He,2013) According to the literature that can be referred to, previous scholars only carried out research on cultural tourism in places with particularly strong ancient culture such as Xi'an and Jingdezhen, or only analyzed the development status of integrated tourism in Pingtan International Tourism Island. This paper refers to the research of scholars to analyze the feasibility of Pingtan as an international tourism island to develop cultural tourism resources.

\section{ANALYSIS OF THE CURRENT SitUATION OF CULTURAL TOURISM RESOURCES DEVELOPMENT IN PINGTAN TOURISM ISLAND}

\section{A. What is Pingtan International Tourism Island?}

Pingtan is located in the eastern of Fujian Province, facing Taiwan across the sea. It is the closest place to Taiwan Island and the mainland of China. Pingtan, referred to as "Lan", is commonly known as Hai tan and the sea mountain, a comprehensive experimental area under the jurisdiction of Fujian Province. On August 23, 2016, the State Council issued the "Reply of the State Council on the Construction Plan of Pingtan International Tourism Island". The construction of Pingtan International Tourism Island was officially on the right track. Spare no effort to build Pingtan into economic tourism development, social harmony, beautiful environment, unique characteristics and the international tourist islands that compatriots on both Taiwanese and the mainland residents is not only the characteristics of Pingtan, but also the top priority of Pingtan's work.

\section{B. The meaning of cultural tourism industry}

The cultural tourism industry mainly refers to the tourism industry developed by humanities and tourism resources. It is a part of the tourism industry generated to meet people's cultural tourism consumption needs and is an important part of the tourism industry. It takes the geographical difference of tourism culture as the incentive, and the process of collision and interaction of culture gives people a kind of transcendent cultural feeling. This kind of cultural feeling takes the tourist spot that contains the cultural connotation as the carrier, which has manifested the esthetic appeal the stimulation function, the education enlightenment function and the nationality and religious emotion sustenance function. At the same time, cultural tourism has the characteristics of nationality, artistry, mystery, diversity and interactivity, which enables tourists to experience the joyful process of tourism while also experiencing the cultural connotation of tourism resources.

\section{The highly favored cultural tourism industry}

In recent years, with the rapid development of China's economy, people's living standards have improved, and the demand for spiritual culture has also increased. Therefore, a large part of the people's income is used for tourism. According to the National Bureau of Statistics, since 2014-
2017, the economic income brought by China's tourism volume and tourism development has been increasing year by year (Fig. 1).At the same time, with the advent of the low-carbon economy era, the two major industries of culture and tourism have gradually become the "green sunrise industry" with priority development in the world's major countries.[4]

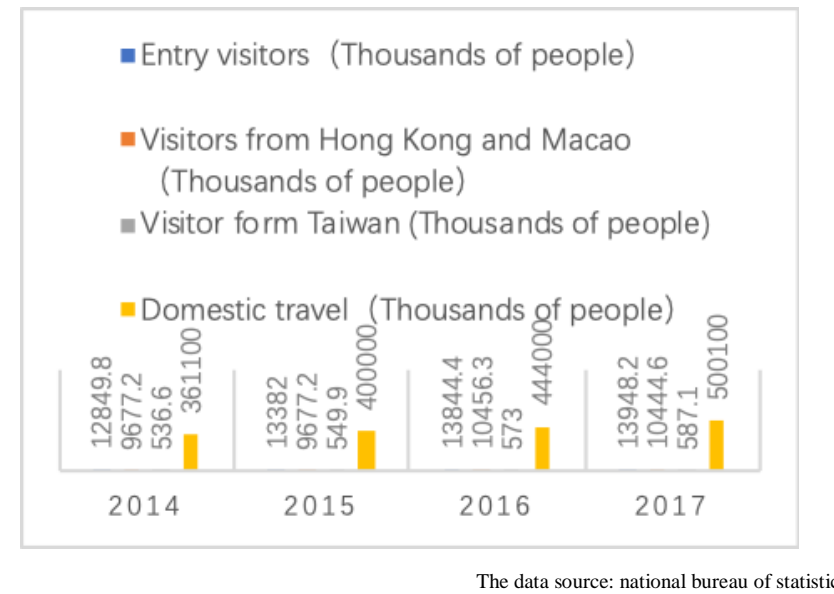

Fig. 1. 2014-2017 China's tourism development

Since the 18th National Congress of the Communist Party of China, China has paid more and more attention to the development of the cultural tourism industry and has continuously increased policy support and investment. The development of cultural tourism brands continued to advance, cultural tourism management and services continued to strengthen, and the cultural tourism market already had a certain scale. Based on the analysis of the status quo of cultural tourism development, the provinces and municipalities have continuously explored and developed their own cultural tourism projects based on the cultural characteristics and traditions of the region and presented the development trend of industrialization.

\section{The bright future of Pingtan Tourism Island Cultural Tourism Industry}

The Party Central Committee has always attached importance to the development of cultural industries and cultural undertakings. Therefore, the development of cultural tourism, which is in sync with the times, has emerged. In recent years, the cultural tourism industry has been gaining momentum, from market growth to national policies to industrial investment, which has become the main engine that leads China's consumption upgrade. In the context of globalization and urbanization in the new era, new scenes, new technologies, new products, and new models will bring "cultural tourism plus" to be splendid. The development of China's cultural tourism industry from the burgeoning industry to today, whether it is the source market or operating income, has become one of the leading forces in the development of the world tourism market. As China promotes the "Belt and Road" strategy and the deepening of free trade policy, the opening up of the service industry will certainly promote the further internationalization of the cultural tourism industry. Thus, bringing new development opportunities for the cultural tourism industry. Pingtan County's 2019 government work 
report pointed out that it will fully integrate the "Belt and Road" construction at a new starting point, and will implement silk road shipping, silk road flying, international cooperation demonstration park construction, construction of overseas economic and trade cooperation key parks, and construction of fishery culture bases. Cultural tourism branding is listed as a key task.

\section{PROBlems IN THE DEVELOPMENT OF TOURISM RESOURCES IN PINGTAN TOURISM ISLAND}

In November 2011, the State Council approved the "Pingtan Comprehensive Experimental Zone Overall Development Plan", clearly defining tourism as one of the four leading industries in Pingtan's development. Since the establishment of Pingtan International Tourism Island, the tourism economy of Pingtan Tourist Island has developed rapidly. In 2018, it basically achieved 5.8 million visitors a year, and the total tourism revenue exceeded 6 billion yuan. During the Spring Festival this year, the region received a total of 258,519 visitors, an increase of $48.55 \%$ over the same period of last year; tourism income of 231,146,800 yuan, an increase of $77.38 \%$, the region's tourism market opened the door. However, Pingtan tourism has the following problems due to various factors in the process of rapid development.

\section{A. Lack of regional culture integration and innovation}

Pingtan has a long history. In addition to China's more unified festivals, Pingtan also has a very special festival, the Nine-Year Festival, also known as "the Filial Festival", which is derived from the legend of "Mu Lian, who saved her mother." There are many folk stories in Pingtan that have been passed down to the present, such as the dumb emperor, the live stone lion, the Niu Shan king, the legend of Haiyan, the legend of Bihu, and the legend of Pingtan Tan. However, the development and design of the tourist resources of Pingtan Tourism Island is old, and it does not reflect the essence and charm of local culture, and it is impossible to realize the scale development of the cultural industry.

\section{B. Pingtan Tourism Island tourism resources have not been maximized}

As the fifth largest island in China and the largest island in Fujian, Pingtan Island enjoys unique geographical conditions and boasts beautiful island scenery and rich and diverse tourism resources. However, tourism products are underdeveloped, tourism design is single, mainly based on routes; leisure cultural products are lacking, mainly tourism; lack of tourist souvenirs, mainly seafood; lack of shopping facilities, mainly fishermen, stalls, small markets Mainly; due to insufficient supply of products, tourists' demand for consumption on the island is difficult to release.

\section{COUnTERMEASURES FOR DEVELOPING CUlTural TOURISM RESOURCES OF PINGTAN}

\section{A. Combination of protection and construction}

Driven by the construction of "beautiful villages" in Fujian Province, Pingtan ancient dwellings are the crystallization of the wisdom of countless generations of residents in Pingtan. They are representatives of local culture and valuable local architectural heritage. In the rural tourism planning, traditional dwellings can not only be transformed into modern homestays, but also should pay more attention to the relationship between Pingtan marine culture and fishery culture and the cultural connotation reflected by its own architectural structure. As a cultural carrier carrying the spiritual beliefs of fishermen, folk temples, such as Mazu, Mrs. Linshui, and the city's grandfather, are often worshipped by the people of Fujian and Taiwan, and it is easy to reach a consensus on belief and culture. Pingtan should maintain historical and cultural sites, storytelling historical and cultural stories, promote the development of Pingtan cultural tourism resources, and create cultural experience tourism.

\section{B. Extend the creative culture tourism industry chain.}

Create a cultural tourism industry cluster and form a scale effect.[5] For example, the creation of large-scale historical and cultural performances; the development of Pingtan County's characteristic cultural scenes; and the creation of the "PutianChangle-Pingtan" cultural tourism industry chain. In order to promote the excellent traditional culture of China, in 2018, the Ministry of Culture and Tourism organized the jury and naming of the "Hometown of Chinese Folk Culture and Art" in 2018-2020.Among them, Changle City, Fujian Province, was selected as the "Hometown of Chinese Folk Culture and Art" by $\mathrm{Yu}$ Opera and Putian City. First of all, Pingtan has a superior geographical position and is adjacent to Fuqing City, Changle and Putian City. Secondly, from 2003 to 2005, Pingtan County successfully hosted the 3rd International Sand Sculpture Festival. During the Sand Sculpture Festival, a literary evening, a sand sculpture beer carnival, a sand sculpture body painting show, a minority style show, a large kite release, and a sand sculpture photography contest were held. The Nan Shaolin Martial Arts Competition, the first elite male model contest in Fujian Province, the first Miss Beach contest in Fujian Province, and the fashion show are all kinds of supporting activities combining entertainment and appreciation. While developing cultural tourism, we can link Putian and Changle, integrate the development of local catering, hotel accommodation, transportation, film and television culture creation, and special tourist souvenir manufacturing to create a "Putian-Changle-Pingtan" cultural tourism industry chain.

\section{CONCLUSION}

Pingtan, combined with analysis of this paper, as an international tourist island and its development of cultural tourism resources has certain rationality both under political conditions and in its own advantages. The development of cultural tourism industry in Pingtan Tourism Island is promising. The construction of Pingtan Island cultural tourism economic chain in Fujian Province has unique geographical and humanistic advantages. While utilizing its advantages, it should construct a cultural tourism economic chain operation mode with government regulation, local leading, market regulation, expert guidance and social supervision. Besides, dig the resources of traditional folklore, culture and other tourism 
projects of ethnic minorities such as the nationality of $\mathrm{Yi}$, and at the same time focus on the development of creative cultural tourism products and projects to realize the integrated development model of traditional cultural tourism and multimedia era. Therefore, it is hoped that the analysis and countermeasures of the development of cultural tourism resources in Pingtan Island can promote the comprehensive development of tourism economy.

\section{REFERENCES}

[1] Report of Pingtan county government in 2019. Minnan Fujian net. January 22, 2019.

[2] Yunxia Li. Reflections on mass cultural tourism, \} Current media , 12 [J] 2018, pp.137-138.

[3] Yougui He. J. Knowledge Economy, 13, 2013, pp.113.

[4] Yiying Lu. Development and utilization of cultural industry-a planning case of combining Lanxi water culture with tourism, [J] Contemporary tourism (gore travel), 6, 2018.

[5] Chun Zhang, Mei Zhang. Research on the development of tourism of Jingdezhen cultural and creative industry, J. China ceramic industry, 1, 2019, pp. 45-49. 